\title{
11
}

\section{PROGRAM KESEJAHTERAAN SOSIAL ANAK(PKSA) DALAM MEMENUHI KESEJAHTERAAN ANAK JALANAN}

\author{
Oleh: \\ Yasmin Anwar Putri, Nandang Mulyana, \& Risna Resnawaty \\ Email: \\ (mulyananandang@gmail.com; happytruz@yahoo.com)
}

\begin{abstract}
ABSTRAK
Keberadaan anak jalanan merupakan akibat langsung dari pemenuhan kebutuhan yang tidak terpenuhi. Anak yang merupakan bagian dari keluarga, tidak mampu memenuhi kebutuhan fisik, psikis, sosial, dan spiritual. Anak tidak mencukupi kebutuhan makan, pendidikan, rasa nyaman hingga tidak mampu menjalankan fungsi sosial sebagai anak secara wajar. Belum adanya Undangundang khusus mengenai anak jalanan seperti peraturan daerah, peraturan pusat, atau yang lainnya juga menyebabkan aparat penegak hukum sulit mengadakan tindakan hukum dan pencegahan anakanak untuk tidak berada di jalan. Sehingga perlu adanya dukungan dari keluarga maupun pemerintah untuk memulihkan keberfungsian sosial anak itu sendiri. Salah satu program untuk menangani anak jalanan yaitu Program Kesejahteraan Sosial Anak (PKSA). Program ini dibentuk atas dasar semakin bertambahnya anak-anak jalanan di Indonesia. Secara konseptual PKSA lebih komprehensif dan berkelanjutan dibandingkan program pelayanan sosial anak pada tahun-tahun sebelumnya karena sudah berdasarkan pendekatan anak, orang tua dan keluarga (family based care), dan kepada masyarakat yaitu Lembaga kesejahteraan sosial yang khusus menangani anak (LKSA). PKSA dirancang sebagai upaya yang terarah, terpadu dan berkelanjutan yang dilakukan pemerintah, pemerintah daerah dan masyarakat dalam bentuk pelayanan dan bantuan kesejahteraan sosial anak bersyarat yang meliputi bantuan sosial/subsidi pemenuhan kebutuhan dasar, peningkatan aksesibilitas terhadap pelayanan sosial dasar (akte kelahiran, pendidikan, kesehatan, tempat tinggal dan air bersih, rekreasi, keterampilan dan lain-lain), penguatan dan tanggungjawab orangtua/keluarga dalam pengasuhan dan perlindungan anak, penguatan kelembagaan kesejahteraan sosial anak.

Kata Kunci : Program Kesejahteraan Sosial Anak, kesejahteraan anak
\end{abstract}

\section{PENDAHULUAN}

Kesejahteraan dan perlindungan anak di Indonesia telah diatur oleh berbagai kebijakan dan program, antara lain mulai dari Undang-Undang Dasar 1945, dimana anaak terlantar dan fakir miskin dipelihara oleh negara. Undang-Undang Republik Indonesia Nomor 4 Tahun 1979 Tentang Kesejahteraan Anak telah mengatur tentang hak anak yaitu "anak berhak atas kesejahteraan, perawatan, asuhan dan bimbingan berdasarkan kasih sayang baik dalam keluarganya maupun dalam asuhan khusus untuk tumbuh dan berkembang dengan wajar", dan tanggung jawab orang tua yaitu bahwa "orang tua bertanggung jawab teradap kesejahteraan anak".

Pada konteks kesejahteraan sosial anak, permasalahannya adalah belum terpenuhinya hakhak dasar anak seperti hak sipil dan kebebasan fundamental, kesehatan, gizi, air dan sanitasi lingkungan, dan pendidikan. Dalam konteks pengasuhan anak, permasalahan dilihat dari pelaksanaan kewajiban orang tua atau orang tua penggantidan lembaga kesejahteraan sosial anak (LKSA) dalam 
pengasuhan anak. sedangkan dalam isu perlindungan anak yaitu belum terpenuhinya hak-hak anak untuk memperoleh perlindungan dari pihak-pihak yang berkewajiban melindungi anak seperti keluarga, masyarakat, atau lembaga perlindungan anak.

Permasalahan anak menjadi perhatian besar sejak lama. Berdasarkan data Biro Pusat Statistik (2006), jumlah anak Indonesia di bawah 18 tahun mencapai 79.898.000 jiwa, dan mengalami penigkatan menjadi 85.146.000 jiwa pada tahun 2008. Sementara itu, Kementrian Sosial melalui Program Kesejahteraan Sosial Anak (PKSA), sejak tahun 2005 sampai 2013, rata-rata baru bisa menangani 3,7\% atau sekitar 170.000 anak/tahun.

Pada tahun 1990 Indonesia telah meratifikasi Konvensi Hak Anak (KHA) melalui Keppres 36/1990 pada tanggal 25 Agustus 1990 dimana substansi inti dari KHA adalah adanya hak asasi yang dimiliki anak dan ada tanggung jawab Negara-Pemerintah-Masyarakat-dan Orang tua untuk kepentingan terbaik bagi anak secara optimal. Kemudian KHA dikuatkan dengan terbitnya UndangUndang Nomor 23 tahun 2002 Tentang Perlindungan Anak yang mengatur tentang Hak dan Kewajiban Anak, serta kewajiban dan tanggung jawab negara, pemerintah, masyarakat, keluarga, dan orang tua. Di samping itu juga diatur tentang kuasa asuh, perwalian, pengasuhan dan pengangkatan anak, serta penyelenggaraan perlindungan.

Di lingkup Kementrian Sosial (selanjutnya disebut Kemensos) untuk mempercepat penanganan masalah sosia; anak, pada tahun 2009 Direktorat Kesejahteraan Sosial

Anak mulai mengembangkan Program Kesejahteraan Sosial Anak (PKSA) melalui kegiatan uji coba penanganan anak jalanan di lima wilayah yaitu Jawab Barat, DKI Jakarta, Lampung, Sulawesi Selatan, dan Yogyakarta. PKSA dikuatkan melalui kebijakan pemerintah yaitu keluarnya Instruksi Presiden Nomor 1 Tahun 2010 Tentang Percepatan Pelaksanaan Prioritas Pembangunan Nasional, dimana diperlukan penyempurnaan program bantuan sosial berbasis keluarga khususnya bidang kesejahteraan sosial anak balita terlantar, anak terlantar, anak jalanan, anak dengan disabilitas, anak yang berhadapan dengan hukum. Selanjutnya PKSA dikuatkan lagi dengan Instruksi Presiden Nomor 3 Tahun 2010 Tentang Program Pembangunan yang Berkeadilan, yang menetapkan PKSA sebagai program prioritas nasional salah satunya PKS-Anak Jalanan. Selanjutnya, sebagai tindak lanjut dari Instruksi Presiden, telah ditetapkan Keputusan Menteri Sosial RI Nomor 15A/HUK/2010 Tentang Panduan Umum Kesejahteraan Sosial Anak (PKSA).

Pada tahun 2013, penerima manfaat Program Kesejahteraan Sosial Anak sebesar 175.611 anak. Program ini bertujuan untuk mewujudkan pemenuhan hak dasar anak dan perlindungan terhadap anak dari keterlantaran, kekerasan, eksploitasi, dan diskriminasi sehingga tumbuh kembang, kelangsungan hidup, dan partisipasi anak dapat terwujud. PKSA juga mendorong perubahan paradigma dalam pengasuhan, peningkatan kesadaran masyarakat, penguatan tanggung jawab orang tua/keluarga dan masyarakat, serta mekanisme pemenuhan kebutuhan dasar anak yang dapat merespon keberagaman kebutuhan melalui tabungan.

Program Kesejahteraan Sosial Anak merupakan bagian dari sistem Kesejahteraan Sosial secara luas. Kesejahteraan sosial sendiri adalah kondisi terpenuhinya kebutuhan material, spiritual, dan sosial warga negara agar dapat hidup layak dan mampu mengembangkan diri, sehingga dapat melaksanakan fungsi sosialnya (menurut Undang-Undang nomor 11 Tahun 2009 Tentang Kesejahteraan Sosial). Dalam konsep kesejahteraan sosial, harus terdapat aspek pencegahan (primer), penanganan resiko (sekunder), maupun penaganan korban (tersier).

Program Kesejahteraan Sosial Anak juga mencakup aspek perlindungan anak. disini, titik berat ada pada penanganan masalah yang dialami anak. Konsep ini masuk dalam pelayanan tersier. Dalam PKSA, terdapat 5 cluster pelayanan anak, salah satunya adalah cluster Anak Jalanan.

\section{PROGRAM KESEJAHTERAAN SOSIAL ANAK (PKSA) DALAM MEMENUHI KESEJAHTERAAN ANAK JALANAN}


Permasalahan anak jalanan merupakan masalah yang sangat kompleks bahkan haltersebutmembentuk sebuah lingkaran yang berujung yang sulit dilihat ujung pangkalnya. Kalanganaparat hukum, polisi misalnya, memandang bahwa payung kebijakan yang dapat digunakanuntuk menangani anak jalanan belum ada. Mereka sulit untuk melakukan tindakan hukumberhubung tidak adanya undang-undang khusus mengenai anak jalanan seperti misalnyaperaturan daerah, peraturan pusat atau yang lainnya sehingga dirasa sulit mengadakanpencegahan agar anak-anak tidak berada dijalan.

Namun, disisi lain dapat dikatakan bahwa anak jalanan mengalami kondisi yang tidak menyenangkan baik secara fisik, psikis, sosial, maupun spirirual. Dengan kata lain anak jalanan umumnya belum berada dalam kesejahteraan sosial dimana kesejahteraan sosial adalah kondisi terpenuhinya kebutuhan material, spiritual, dan sosial warga negara agar dapat hidup layak dan mampu mengembangkan diri, sehingga dapat melaksanakan fungsi sosialnya (menurut UndangUndang nomor 11 Tahun 2009 Tentang Kesejahteraan Sosial).

Kebijakan dan Program Kesejahteraan Sosial Anak (PKSA) pada masa lalu cenderungdilaksanakan secara sektoral, jangkauan pelayanan terbatas, mengedepankan pendekataninstitusi/panti sosial, dan dilaksanakan tanpa rencana strategis nasional. Sedangkan Program Kesejahteraan Sosial Anak (PKSA) sekarang dirancang sebagai upaya yang terarah, terpadu, dan berkelanjutan yang dilakukan pemerintah, pemerintah daerah, dan masyarakat dalam bentuk pelayanan sosial dan bantuan kesejahteraan sosial anak bersyarat yang meliputi :

1. Bantuan sosial/subsidi pemenuhan hak dasar seperti akta kelahiran, tempat tinggal, nutrisi, air bersih, dan lain-lain.

2. Peningkatan aksesibilitas terhadap pelayanan sosia dasar seperti akses pendidikan dasar, akses pelayanan kesehatan, akses pelayanan rehabilitasi sosial, dan lain-lain.

3. Pengembangan potensi diri dan kreativitas anak

4. Penguatan tanggung jawab orang tua/keluarga dalam pengasuhan dan perlindungan anak.

5. Penguatan tanggung jawab orang tua/keluarga dalam pengasuhan dan perlindungan anak

6. Penguatan kelembagaan kesejahteraan sosial anak

PKSA yang dilaksanakan dengan efektif seharusnya membawa beberapa dampak positif bagi banyak pihak, antara lain bagi penerima manfaat (klien), keluarga, masyarakat, dan pemerintah daerah. Hal-hal yang seharusnya didapatkan anak jalanan terkait dengan PKS-Anjal yaitu anak kembali ke sekolah, anak mendapat akses ke Puskesmas bila sakit melalui Kartu sehat, presentase anak turun ke jalan menurun baik dari segi jumlah dan lama di jalan, memperoleh kemudahan dalam mendapatkan akses fasilitas dan pengobatan kesehatan, memperoleh kemudahan dalam mendapatkan informasi tentang bahaya-bahaya termasuk bahaya di jalanan, memperoleh kemudahan mendapatkan perlindungan dari tindak kekerasan termasuk pelecehan seksual, memperoleh kemudahan mendapat perlindungan termasuk penelantaran dari ibunya.

Masalah anak jalanan ini tidak bisa terlepas dari bantuan berbagai pihak. Untuk mengeluarkan anak dari jalan diperlukan dukungan keluarga dan lingkungan, namun dalam kenyataannya masih ada keluarga yang kurang mendukung dalam arti masih menyuruh anaknya turun ke jalan untuk membantu ekonomi keluarga dan juga masih ada lingkungan yang kurang mendukung yaitu masih memberikan stigma kepada anak jalanan dan belum melibatkan anak di kegiatan lingkungan. Padahal salah satu upaya PKSA adalah penguatan tanggung jawab orang tua/keluarga dalam pengasuhan dan perlindungan anak misalnya meningkatnya peran orang tua dalam pemenuhan makanan bergizi, orang tua mengakseskan anaknya ke pelayanan kesehatan dan pelayanan pendidikan.

Anak jalanan merupakan bagian dari anak yaitu siapa saja yang berusia di bawah 18 tahun Setiap anak mempunyai hak yang sama untuk hidup, tumbuh dan berkembang secaramaksimal sesuai potensinya. Secara berlapis, dimulai dari lingkar keluarga dan kerabat,masyarakat sekitar, pemerintah lokal sampai pusat, hingga masyarakat internasional yangberkewajiban untuk menghormati, 
melindungi, dan mengupayakan pemenuhan atas hak-hakanak. Jika setiap lapisan pemangku tugas tersebut dapat berfungsi dengan baik danmampu menjalankan kewajiban dan tanggungjawabnya, maka anak akan dapat memilikikehidupan berkualitas yang memungkinkannya tumbuh-kembang secara optimal sesuaipotensinya. Meskipun banyak upaya telah dilakukan, masih banyak anak Indonesia masih hidup dalam beragam situasi sulit yang membuat kualitas tumbuh kembang dankelangsungan hidupnya terancam termasuk anak jalanan.

Sebelumnya masalah anak dana masalah-masalah perlindunga anak hanya difokuskan pada anak. keluarga dan masyarakat belum banyak disentuh. Misalnya pada penanganan anak jalanan ini banyak diserahkan ke lembaga atau panti sosial dimana di dalam penanganannya oran tua atau keluarga pengganti kurang dilibatkan. Anak lebih banyak dicabut dari lingkungan keluarga. Pelayanan dalam panti hanya berfokus pada klien bukan sistem klien, maksudnya panti sosial belum melaksanakan intervensi kepada keluarga dan masyarakat dari proses pelayanan sesuai dengan prinsip-prinsip pekerjaan sosial. Padahal keluarga menjadi salah satu faktor penting pendukung tumbuh kembangnya anak. Peran keluarga dan masyarakat menjadi penting, mengingat pemenuhan hak-hak dan akses kebutuhan seseorang tidak bisa dipenuhi dan harus dipenuhi oleh panti sosial.

\section{PENUTUP}

Rekomendasi yang akan saya berikan dilihat dari berbagai aspek diantaranya adalah sebagai berikut

1. Kebijakan : harmonisasi kebijakan yang berupa peraturan perundang-undangan yang terkait dengan kesejahteraan dan perlindungan anak, edukasi yang tepat dan sama bagi pelaksana program kesejahteraan dan perlindungan anak, pemantauan daerah yang belum menindaklanjuti Undang-Undang atau peraturan di tingkat nasional dan bagi yang telah menindaklanjuti diperkuat dalam substansinya, adanya sinergi dalam implementasi kebijakan antar kementrian terkait juga ditindaklanjuti oleh aparatur tingkat provinsi dan kabupaten/kota

2. Manajemen keuangan :

Sumber keuangan yang ada baik dari APBN, APBD Provinsi dan Kabupaten/Kota, dana masyarakat dan bantuan luar negeri di sinergikan untuk program terutama untuk anak bermasalah juga diatur dan disesuaikan sedemikian rupa jumlahnya dengan kebutuhan.

3. Manajemen SDM :

Ditingkatkan kuantitas dan kualitas SDM misalnya pengetahuan dalam menangani kluster tertentu, terutama pendamping yang berasal dari masyarakat. Untuk meningkatkan kapasitas TKSA, pendamping/pekerja sosial dari LKSA di bidang kesejahteraan dan perlindungan anak khususnya lagi dalam penanganan masing-masing kluster diberikan pendidikan dan pelatihan yang bisa dilaksanakan oleh Pusat Pendidikan dan Latihan Kesejahteraan Sosial di Jakarta dan Balai Besar Pendidikan dan Pelatihan Kesejahteraan Sosial yang keberadaannya ada di enam wilayah kerja yaitu Padang, Bandung, Yogyakarta, Banjarmasin, Makasar, dan Papua.

4. Manajemen data :

pendataan lebih mendalam untuk perlakuan salah, tindak kekerasan, dan eksploitasi, tidak hanya berasal dari yang melapor saja. Tapi dilakukan cara lain agar hal-hal tersebut bisa diketahui.

5. Perlu adanya pengawasan dengan sistem yang memiliki indikator baku misalnya untuk indikator kualitas suatu program.

6. Program yang diberikan disesuaikan dengan nilai dan norma yang ada di tempat sasaran program itu diberikan.

7. LKSA dalam pelaksanaan harus melalukan strategi lain agar tidak selalu bergantung pada dana operasional yang jumlahnya terbatas, misalnya bekerjasama dengan berbagai CSR perusahaan. 
8. Adanya peningkatan kapasitas keluarga/keluarga pengganti yang dilakukan oleh pekerja sosial anak yang bernaung di bawah LKSA melalui kunjungan rumah.

9. Anak-anak untuk umur tertentu, remaja dan keluarga, dan masyaraat dilibatkan dalam proses asesmen, penyelesaian masalah, pelaksanaan, dan evaluasi.

10. Pemberdayaan ekonomi keluarga melalui usaha ekonomi produktif (UEP) atau kelompok usaha bersama (KUBE)

11. Kegiatan PKSA disinergikan dengan kegiatan karang taruna dalam hal pencegahan masalah anak jalanan, keterlantaran, kenakalan pada anak, dengan kegiatan pengisian waktu luang dan kegiatan-kegiatan peningkatan kreativitas anak.

12. Pihak-pihak terkait punya keinginan bersama untuk merencanakan, melaksanakan, melakukan pemantauan secara bersama. Masing-masing direktorat terkait punya target atau indikator masing-masing sesuai peranannya. Agar pelaksanaan program menjadi lebih efektif, terkait anggaran tidak akan menumpuk pada satu bagian juga banyak masalah yang sekaligus bisa terselesaikan sekaligus.

13. Sebagai mahasiswa, terutama mahasiswa kesejahteraan sosial mengkaji keilmuan baik dari bangku kelas maupun praktik langsung lewat kegiatan maupun organisasi dalam atau luar kampus untuk memperkaya pengalaman dan persiapan kontribusi untuk penanganan masalah ini.

\section{DAFTAR RUJUKAN}

Astuti, Mulia. Dkk. Penelitian Evaluasi Program-program kesejahteraan sosial di Indonesia, Executif Summary Hasil Penelitian Tahun 2012 Puslitbang Kesejahteraan Sosial oleh Kementrian Sosial Republik Indonesia. Jakarta: P3KS Press

Astuti, M. Kebijakan Kesejahteraan dan Perlindungan Anak, Studi Kasus Evaluasi Program Kesejahteraan Sosial Anak di Provinsi DKI Jakarta, DI. Yogyakarta, dan Provinsi Aceh. 2013. Jakarta: P3KS Press

DirektoratKesejahteraanSosialAnak. 2011. PedomanOperasional PKSA. Jakarta :KementrianSosial RI

Evaluasi Kebijakan Kesejahteraan Sosial, Executif Summary Hasil Penelitian Tahun 2013 Puslitbang Kesejahteraan Sosial oleh Kementrian Sosial Republik Indonesia. Jakarta: P3KS Press

InstruksiPresidenNomor 3 Tahun 2010.Program Pembangunan yangBerkeadilanditetapkanlah Program KesejahteraanSosialAnak (PKSA).

KeputusanMenteriSosialNomor 15A/HUK/2010. PanduanUmum Program

KesejahteraanSosialAnak (PKSA).

KonvensiHakAnakoleh UNICEF padatahun 1989

Suharto, Edi. (2005). MembangunMasyarakat, Memberdayakan Rakyat: KajianStrategis Pembangunan KesejahteraanSosialdanPekerjaanSosial. Bandung: RefikaAditama

Tjokroamidjodjo, bintoro. 1995. Perencanaan Pembangunan. Jakarta:cv. Haji mas agung. http://www.pksa-kemensos.com/ diaksestanggal 25 September 2014 pukul 15.26Pedoman PKSA 2011

Undang-undangRepublik Indonesia Nomor 11/2009 TentangKesejahteraanSosial 